\title{
Discriminação salarial de gênero no Centro-Oeste brasileiro: O preço do trabalho da mulher
}

\author{
Priscila Akimi Hayashi \\ Graduada no Curso de Ciências Econômicas da Universidade Estadual de Londrina/PR \\ Email: priscilakimih@outlook.com
}

Solange de Cassia Inforzato de Souza

Professora associada do Curso de Economia e do Programa de Mestrado em Economia Regional da Universidade Estadual de Londrina/PR

Email: solangecassia@uol.com.br

\section{Magno Rogério Gomes}

Professor assistente do Curso de Economia da Universidade Estadual de Londrina/PR

Email: magnorg86@gmail.com

\section{Katy Maia}

Professora associada do Curso de Economia e do Programa de Mestrado em Economia Regional da Universidade Estadual de Londrina/PR

Email: katymaia@terra.com.br

Resumo: Este trabalho tem como objetivo investigar a discriminação salarial entre homens e mulheres na região Centro-Oeste do Brasil. Para tanto, realizou-se a decomposição salarial de Oaxaca-Blinder, a partir dos microdados das PNADs 2003 e 2013. Verificou-se que: i) a educação e a experiência no trabalho contribuíram positivamente para maiores níveis salariais, todavia, os salários masculinos foram superiores aos femininos e o hiato salarial por sexo elevou-se na região; ii) uma parcela deste diferencial é atribuída ao fator discriminante; iii) houve um aumento da discriminação salarial entre os gêneros na região, contrariamente ao que ocorreu no âmbito nacional; e iv) as diferenças e a discriminação de salários entre homens e mulheres não brancos foram inferiores aos brancos, e elevaram-se para os dois grupos de cor de pele.

Palavras-chave: Discriminação salarial. Gênero. Região Centro-Oeste.

Abstract: This paper aims to investigate wage discrimination between men and women in the Center-West region of Brazil. For that, the wage decomposition of Oaxaca-Blinder was made from the microdata of the PNADs 2003 and 2013. It was verified that: i) education and work experience contributed positively to higher wage levels, however, male wages were higher than the female ones and the wage gap for sex increased in the region; ii) a portion of this differential is attributed to the discriminant factor; iii) there was an increase in wage discrimination between genders in the region, contrary to what happened at the national level; and (iv) differences and wage discrimination between non-white men and women were lower than white and rose to the two skin color groups. Key-words: Wage discrimination. Gender. Center-West. JEL Code: J16; J31. 


\section{INTRODUÇÃO}

Os estudos voltados para a temática da desigualdade de renda e de rendimentos têm se tornado cada vez mais frequentes, principalmente com enfoque em países latino-americanos, como o caso brasileiro. Trabalhos como os de Langoni (1973), Bonelli e Ramos (1993) e Barros e Mendonça (1995), por exemplo, comprovaram a elevação nos graus de concentração de renda e de rendimentos recorrentes no Brasil desde meados da década de 1960.

A partir da década de 1970, com o notável aumento da participação feminina no mercado de trabalho brasileiro, questões referentes ao comportamento da distribuição salarial segundo o gênero passaram a ser levantadas e alavancaram estudos como os de Lovell (1994), Leme e Wajnman (2000), Carvalho, Néri e Silva (2006), Cambota e Pontes (2007) e Manganelli (2013). Estes trabalhos não apenas detectaram a ocorrência de disparidades salariais entre homens e mulheres no país, como também atribuíram uma parcela dessas diferenças a um fator discriminante.

Na teoria econômica, as diferenças salariais são explicadas em grande parte pela teoria do capital humano a qual, segundo Schultz (1961) e Becker (1962), pressupõe que trabalhadores com capacidades produtivas diferentes, nível educacional e experiência, incorporam diferentes níveis de capital que resultam em diferentes níveis de remunerações. A teoria da segmentação valoriza o posto de trabalho e leva em consideração os diferentes segmentos do mercado de trabalho para explicitar as diferenças salariais. A teoria da discriminação explica a ocorrência de hiatos salariais entre indivíduos com mesmo nível de capital humano e alocados em postos de trabalho idênticos, pelas características não produtivas distintas, como sexo, cor da pele, e outras.

Empiricamente, a dimensão continental brasileira inspirou estudos como os de Araújo e Ribeiro (2002) e Bohnenberger (2005), que analisaram as cinco macrorregiões brasileiras e evidenciaram a presença de distintos graus de discriminação salarial entre os gêneros em cada uma das regiões. Em particular, a região Centro-Oeste revelou o segundo maior grau de segregação ocupacional entre as demais macrorregiões do país.

Esta região, de acordo com Silva, Yasunaka e Melo (2012), apresentou a segunda maior taxa de crescimento do Brasil em 2010, 1,91\% (incluindo o Distrito Federal). Ainda, sua população economicamente ativa em 2014 era de 8.084.718 pessoas, a renda média domiciliar per capita de $\mathrm{R} \$$ 1.279,01, e a população composta em sua maioria por indivíduos pardos, seguidos de brancos, e pretos, segundo o IPEA (2015).

Neste contexto, o principal objetivo desta pesquisa é medir e analisar a discriminação salarial na região Centro-Oeste em 2003 e 2013, através da estimação de equação salarial proposta por Mincer (1974), e da decomposição dos salários desenvolvida por Oaxaca-Blinder (1973). Para isso, o trabalho encontra-se estruturado da seguinte maneira: além desta introdução, a seção 2 traz os arcabouços teórico e empírico acerca das diferenças salariais e da discriminação por gênero e cor no Brasil e no Centro-Oeste. Na terceira seção segue o procedimento metodológico adotado. A seção 4 procura expor e tratar os resultados obtidos na pesquisa. Por fim, a quinta e última seção traz as principais conclusões inferidas. 
p. 15 - Discriminação salarial de gênero no Centro-Oeste brasileiro: O preço do trabalho da mulher

\section{DIFERENÇAS SALARIAIS NA TEORIA ECONÔMICA E AS EVIDÊNCIAS EMPÍRICAS PARA O BRASIL E REGIÃO CENTRO-OESTE}

\subsection{Diferenças salariais na teoria econômica}

As diferenças salariais em um sistema econômico vieram a ser estudadas com maior profundidade nas décadas de 1950 e 1960, com os estudos do capital humano, cujos pioneiros acerca do assunto foram Schultz (1961) e Becker (1962). Ao estudar a taxa de retorno salarial para o ensino médio e superior da população estadunidense da década de 1950, Becker (1962) introduz uma ideia preliminar de recursos físicos e recursos intangíveis presentes na determinação dos níveis salariais de um país, sendo os recursos intangíveis investimentos em capacitação intelectual e profissional.

No entanto, críticas surgiram por volta dos anos 1970 e a teoria do mercado segmentado se disseminou. Segundo Lima (1980), a teoria da segmentação propõe que o mercado de trabalho esteja dividido em dois segmentos, sendo o primeiro conhecido como o mercado de trabalho primário, onde de fato se observam os pressupostos sugeridos pela teoria do capital humano: maiores níveis salariais atribuídos a maiores níveis educacionais; e o segundo segmento, conhecido como o mercado de trabalho secundário, onde o grau de escolaridade tem baixa ou praticamente nula influência sobre a determinação dos salários. Isso se deve às características inerentes ao mercado de trabalho secundário como alta rotatividade da mão de obra, salários relativamente baixos, má condições de trabalho, baixa produtividade, altos níveis de desemprego, mínimo de qualificação necessária e oportunidades mínimas de aprendizagem e promoções.

Todavia, estudos posteriores - principalmente após a década de 70 - observam que muito embora a teoria do capital humano e a teoria da segmentação expliquem em grande parte os hiatos salariais, há ainda uma parcela dessas diferenças que foge destas abordagens teóricas. Com isso, ao destacar as questões raciais e de gêneros, Lovell (1994) aponta para o que se tem por "discriminação no mercado de trabalho".

Borjas (2012) procura demonstrar que na teoria da discriminação as diferenças nos ganhos salariais ou até mesmo nas oportunidades de empregos podem existir mesmo entre indivíduos igualmente capacitados, e (ou) igualmente alocados no mercado de trabalho. De acordo com a teoria, esta diferenciação deve-se às características não produtivas do indivíduo como: cor de pele, gênero, origem nacional, orientação sexual ou entre outros aspectos aparentemente irrelevantes à produtividade.

Ehrenberg e Smith (2000) apontam três possíveis fontes para de discriminação no mercado: (1) o preconceito pessoal, que abrange as discriminações do cliente, do empregador e do empregado; (2) a discriminação estatística, que está relacionada com as informações do grupo obtidas pelos empregadores, e (3) os modelos do poder de monopólio, os quais, grosso modo, sugerem que os trabalhadores estejam divididos em "castas" diferentes (de acordo com seu sexo e etnia) e que não competem entre si.

Partindo-se das ideias da teoria do capital humano, da segmentação (ou mercado segmentado) e da discriminação, a próxima seção elabora um breve 
levantamento de trabalhos empíricos sobre o assunto.

\subsection{Desigualdade de renda e diferença de salários no Brasil}

Lovell (1994) trata das possíveis ocorrências de discriminações no mercado de trabalho brasileiro entre 1960 e 1980, e aponta a relevância da questão da raça e do gênero no Brasil devido ao grande número de habitantes com descendência africana que o país revela, além também da maior participação feminina no mercado de trabalho brasileiro. Depois de controlar e isolar as diferenças de qualificação constatou que, no período, os homens ganhavam mais do que as mulheres e os brancos ganhavam substancialmente mais do que os afro-brasileiros.

Com um trabalho semelhante, Bohnenberger (2005) estuda a presença de discriminação salarial por gênero e raça conjuntamente no país e em suas regiões entre os anos de 1992 e 2003, e conclui que a discriminação de gênero revelou tendência de queda ao longo dos anos, enquanto que a racial apresentou diminuição praticamente ínfima. Regionalmente, o sul do país apresentou a maior diminuição do grau de discriminação contra mulheres brancas e negras, enquanto que no centro-oeste esta evolução foi a mais inexpressiva em relação às demais. Em contrapartida, a respeito da cor de pele, a região centro-oeste foi a que apresentou os menores indícios de discriminação contra homens negros em relação ao restante do país.

Carvalho, Néri e Silva (2006) estudaram igualmente a presença de discriminação por gênero e cor no Brasil em 2003. Além de salientar a contribuição da variável educação como determinante de maiores salários, o estudo apontou que a discriminação é responsável por $97 \%$ do diferencial de salários entre homens brancos e as mulheres pretas ou pardas, ambos tidos como grupos com características extremas de gênero e cor de pele, fato que sugere a ocorrência de "dupla discriminação".

Barros e Mendonça (1996) descrevem as diferenças entre os processos discriminatórios de gênero e cor no Brasil. Quanto aos diferentes fatores que influenciaram as diferenças salariais brasileiras entre brancos e não brancos no início da década de 90, os autores salientaram a desvantagem educacional como o aspecto de maior influência sobre as disparidades da época, além também das desvantagens ocupacionais e locacionais. Já em relação à situação feminina estes aspectos pouco explicaram as diferenças salariais observadas, sugerindo que este hiato seja atribuído a outros determinantes, como a própria discriminação do mercado.

Tratando-se especificamente da questão entre gêneros, Manganelli (2013) avalia o fenômeno do "Teto de Vidro" ${ }^{1}$ no Brasil ao tratar das diferenças salariais entre homens e mulheres. O estudo constatou que em 2009 no Brasil ser mulher resultava um rendimento médio menor do que ser do homem, confirmando a ocorrência do fenômeno. Além disso, apesar da formalização no mercado de trabalho se apresentar como um fator positivo para as mulheres no que tange à segregação ocupacional,

\footnotetext{
1 Segundo a autora, a metáfora advém da existência de certas barreiras invisíveis que impedem a evolução na carreira de mulheres no mercado de trabalho, bem como certo impedimento no crescimento e nos rendimentos mais elevados da população feminina participante deste mercado
} 
p. 17 - Discriminação salarial de gênero no Centro-Oeste brasileiro: O preço do trabalho da mulher

quanto maior o salário na distribuição de rendimentos, maior é o impacto negativo por se estar em uma ocupação feminina.

Cambota e Pontes (2007) analisaram de maneira mais aprofundada as disparidades entre indivíduos de gêneros distintos, porém inseridos em ocupações idênticas. Com base em dados do ano de 2004 para todo o território brasileiro, os autores puderam de fato evidenciar a existência de discriminação intraocupacional contra as mulheres, como já se suponham as hipóteses do estudo. Tal informação ainda revela que esta discriminação torna-se mais perceptível e acentuada quanto maior o grau de escolaridade exigido pelas ocupações.

Além disso, Leme e Wajnman (2000) estudaram o comportamento do hiato salarial entre homens e mulheres entre 1977 e 1997, e inferiram que a escolaridade feminina se mostra superior à masculina desde meados da década de 1950, mas há a persistência do hiato salarial entre homens e mulheres. Houve redução deste hiato salarial, com diminuição da discriminação salarial entre gêneros que ocorre principalmente em regiões fora da região sudeste brasileira.

Já em relação à discriminação salarial de gênero em áreas urbanas das macrorregiões brasileiras em 1995, Araújo e Ribeiro (2002) constataram a presença do fenômeno no país e no que tange à distribuição ocupacional de homens e mulheres, e concluíram que cerca de $40 \%$ da força de trabalho feminina (ou masculina, ou ambas) deveriam ser realocadas para eliminar sua super ou sub-representação em determinadas ocupações nas diferentes regiões urbanas brasileiras. Os maiores diferenciais de salários de gênero encontravam-se no sul e no sudeste brasileiro, ao passo que as menores diferenças foram percebidas no norte e no nordeste. O centrooeste apresentou os salários femininos e masculinos bem acima da média nacional. Além disso, esta região revelou o segundo maior grau de segregação ocupacional dentre as cinco regiões estudadas, e as diferenças em atributos produtivos tenderam a favorecer as mulheres em relação aos homens.

\section{METODOLOGIA}

\subsection{Base de dados}

Para a elaboração deste estudo foram utilizados dados da PNAD (Pesquisa Nacional por Amostra de Domicílios - IBGE), para a região Centro-Oeste ${ }^{2}$, nos anos de 2003 e $2013^{3}$. Foram considerados indivíduos ocupados com idade igual ou acima de 14 anos, analisados através de seus aspectos produtivos como educação (medida em anos de estudos) e experiência no trabalho; e não produtivos como gênero (homens e mulheres) e cor de pele (brancos e não brancos-composto por pardos e pretos-). A pesquisa desconsiderou os indivíduos autodeclarados amarelos e indígenas por sua pouca representatividade para a análise.

Além disso, também foi levado em conta a região onde residem: urbana e não urbana; e variáveis referentes ao mercado de trabalho, como os setores de ocupação,

\footnotetext{
2 Exceto Distrito Federal.

${ }^{3} \mathrm{O}$ ano de 2013 foi escolhido por ser o último ano disponível da PNAD por ocasião desta investigação.
} 
agrícola, indústria da transformação e da construção civil, comércio e serviços. Para a análise foram considerados todos os setores presentes nas categorias da PNAD. A indústria da transformação e da construção foram agrupados em uma única variável da indústria total; e o setor de serviços abarca os setores de alojamento, alimentação, transporte, armazenagem, comunicação, administração pública, educação, saúde, serviços sociais e serviços domésticos.

Ainda nas variáveis do mercado de trabalho, foram incluídas as ocupações: dirigentes, profissionais das ciências e das artes ( $P C A^{\prime} s$ ), técnicos de nível médio e trabalhadores operacionais. Foram igualmente consideradas todas as ocupações presentes na PNAD, com exceção apenas dos membros das forças armadas e auxiliares, e ocupações mal definidas ou não declaradas. Os trabalhadores de serviços administrativos e os vendedores e prestadores de serviços do comércio foram agrupados aos trabalhadores de serviços.

Quanto à forma de inserção no mercado de trabalho, no que tange à posse ou não de carteira assinada por parte população ocupada, foram analisados os trabalhadores formais e informais, incluindo nestes grupos também os empregadores e os trabalhadores por contas-próprias.

Em relação aos rendimentos estudados na análise, os salários foram considerados apenas como o rendimento do trabalho principal, sendo desconsiderados outros tipos de rendimentos. Também foram levados em conta apenas os trabalhadores com rendimento diferente de zero; e devido à comparação temporal dos dados obtidos, os salários de 2003 foram reajustados para preços constantes de 2013 com base no IPCA acumulado.

\subsection{Equação de determinação dos salários de Mincer}

Para realizar a decomposição de diferenças salariais entre gêneros, desenvolvida por Oaxaca-Blinder (1973), inicialmente tomam-se as equações de determinação de salários propostas por Mincer (1974, apud FIUZA-MOURA, 2015, p. 34). Esta equação relaciona as características produtivas dos indivíduos, como anos de estudo e experiência no trabalho, com seus rendimentos, bem como a influência de demais variáveis como a localização ou a ocupação na qual estes indivíduos estão inseridos no mercado de trabalho.

Para este estudo, desenvolveu-se o seguinte modelo log-linear para homens brancos, mulheres brancas, homens não brancos e mulheres não brancas:

$$
\begin{gathered}
L n_{W}=\beta_{0}+\beta_{1} E+\beta_{2} T+\beta_{3} T^{2}+\beta_{4} H+\beta_{5} B+\beta_{6} U r b+\beta_{7} \text { Dir }+\beta_{8} P C_{t} \\
+\beta_{9} \text { Tec }+\beta_{10} \text { For }+\beta_{11} \text { Ind }+\beta_{12} \text { Com }+\beta_{13} \text { Serv }+\mu
\end{gathered}
$$

Sendo $L n_{W}=$ logaritmo natural do salário; $E=$ Estudo (anos de estudo); $T=$ experiência no trabalho; $T^{2}=$ experiência ao quadrado, variável utilizada para captar o retorno da experiência no trabalho ao longo prazo. 
p. 19 - Discriminação salarial de gênero no Centro-Oeste brasileiro: O preço do trabalho da mulher

Além disso, foram consideradas também as influências das variáveis categóricas referentes aos setores: Ind (Indústria), Com (Comércio), Ser (Serviços), sendo omitido o setor Agrícola; às ocupações: Dir (dirigentes), PCA (profissionais das Ciências e das Artes), Tec (técnicos de nível médio), sendo o cargo de Operacionais o omitido da análise; à formalidade do mercado, representada por For, e a região domiciliar denominada por Urb, cuja divisão foi feita entre áreas urbanas e não urbanas.

Após serem determinados os salários da população, utiliza-se o modelo desenvolvido por Oaxaca e Blinder (1973) para a execução da análise das diferenças salariais entre os quatro grupos estudados.

\subsection{Decomposição salarial de Oaxaca-Blinder}

O modelo desenvolvido por Oaxaca e Blinder (1973, apud GOMES, 2016) é utilizado para mensurar o hiato salarial entre dois grupos de trabalhadores e a discriminação salarial. É feita a decomposição das diferenças de salários em dois termos, sendo o primeiro relacionado às diferentes características do trabalhador, tanto produtivas quanto referentes ao mercado de trabalho, ou seja, a parte das diferenças explicadas; e o segundo é relacionado à proxy da discriminação salarial. Para este estudo foi decomposta a seguinte equação de salários:

$$
\left(\bar{Y}^{H}-\bar{Y}^{L}\right)=\left(\beta_{\cdot j}^{H}-\beta_{j}^{L}\right)+\sum_{j} \bar{X}_{j}^{L}\left(\beta_{j}^{H}-\beta_{j}^{L}\right)+\sum_{j} \beta_{j}^{H}\left(\bar{X}_{j}^{H}-\bar{X}_{j}^{L}\right)
$$

Onde, $\left(\bar{Y}^{H}-\bar{Y}^{L}\right)$ representa as diferenças salariais entre dois grupos de trabalhadores; onde o sobrescrito $H$ represente o grupo de indivíduos com os rendimentos maiores e o sobrescrito $L$ o grupo com menor rendimento médio; $\sum_{j} \beta_{j}^{H}\left(\bar{X}_{j}^{H}-\bar{X}_{j}^{L}\right)$ representa a parcela de diferenças explicadas; $\left(\beta_{\cdot j}^{H}-\beta_{j}^{L}\right)+\sum_{j} \bar{X}_{j}^{L}\left(\beta_{j}^{H}-\beta_{j}^{L}\right)$ é atribuído à parcela referente às diferentes remunerações concedidas a indivíduos igualmente capacitados e empregados, ou seja, à discriminação propriamente dita.

Essa decomposição permite o detalhamento das diferenças explicadas e não explicadas, entretanto, esse procedimento incorre no problema de identificação: invariância dos resultados da decomposição frente à escolha arbitrária das variáveis a serem omitidas nos conjuntos de variáveis categóricas utilizadas nas regressões de determinação de salários. Para a correção desse problema utiliza-se o processo de normalização proposto por Yun $(2003,2005)^{4}$.

\footnotetext{
${ }^{4}$ Pelo processo de normalização define-se: $c=\left(\beta_{1 i}+\beta_{2 i}+\beta_{k i}\right) / k=\bar{\beta}_{i}=\sum_{k=1}^{k} \beta_{k i} / k$ Parte explicada $=\sum_{l=1}^{L} \bar{\delta}_{l A}\left(\bar{X}_{l A}-\bar{X}_{l B}\right)+\sum_{m=1}^{M} \sum_{k_{m}=1}^{K_{M}} \beta_{M k m A}^{*}\left(\bar{D}_{M k m A}-\bar{D}_{M k m B}\right)$
}

Parte não explicada (Discriminação)

Simplificando,

$$
=a_{A}^{*}-a_{B}^{*}+\sum_{l=1}^{L} \bar{X}_{l B}\left(\bar{\delta}_{l A}-\bar{\delta}_{l B}\right)+\sum_{m=1}^{M} \sum_{k_{m}=1}^{K_{M}} \bar{D}_{M k m B}\left(\beta_{M k m A}^{*}-\beta_{M k m B}^{*}\right)
$$

$a_{i}^{*}=a_{i}+\sum_{m=1}^{M} \bar{\beta}_{m i} ;$ sendo $i=A, B$ 
Priscila A. Hayashi; Solange de Cassia I. de Souza; Magno R. Gomes e Katy Maia - p.20

\section{DIFERENÇAS SALARIAIS E DISCRIMINAÇÃO DE GÊNERO NA REGIÃO CENTRO-OESTE DO BRASIL: RESULTADOS DA PESQUISA E INTERPRETAÇÃO}

\subsection{Características da população ocupada na região Centro-Oeste brasileira}

Nesta seção segue uma análise descritiva do perfil da população ocupada do Centro-Oeste brasileiro. Em 2003, a região apresentava no total uma população de 4.117.857 indivíduos, entre eles 2.581.655 homens e 1.536.202 mulheres. Em 2013, esta população masculina aumentou para 3.445.523, e a feminina para 2.324 .212 indivíduos.

Em 2003, a maior parte da população ocupada na região residia em área urbana e era composta por indivíduos não brancos, sendo a participação destes de 57,7\% para homens, e 55,3\% para mulheres (Tabela 1). O percentual de homens considerados chefes de família era bastante superior àquele correspondente ao de mulheres $(74,14 \%$ e $26,05 \%$, respectivamente), e estas tinham em média aproximadamente dois filhos. A média de idade masculina era de 36,6 anos, e a feminina de 34,8 anos.

Tabela 1 - Perfil da população ocupada, Centro-Oeste, 2003 - 2013

\begin{tabular}{lcccccc}
\hline \multicolumn{1}{c}{ Variáveis } & \multicolumn{5}{c}{ Centro-Oeste } \\
\hline & \multicolumn{7}{c}{ Homem } & Mulher & Total & Homem & Mulher & Total \\
\hline Idade (média) & 36,60 & 34,80 & 35,93 & 38,11 & 36,65 & 37,52 \\
Experiência (média) & 24,50 & 20,72 & 23,09 & 24,31 & 21,16 & 23,04 \\
Anos de estudo (média) & 6,23 & 8,13 & 6,94 & 8,12 & 9,91 & 8,84 \\
Salário mensal R\$(média) & 1176,42 & 800,46 & 1035,87 & 1895,79 & 1305,51 & 1657,01 \\
Horas trabalho/semana (média) & 47,80 & 38,11 & 44,19 & 43,46 & 37,43 & 41,03 \\
Salário hora R\$ (média) & 6,86 & 5,91 & 6,50 & 12,86 & 11,02 & 12,11 \\
Número de filhos (média) & - & 1,82 & - & - & 1,64 & - \\
Região urbana (\%) & 81 & 92,47 & 85,28 & 87,28 & 93,36 & 89,73 \\
Região rural (\%) & 18,99 & 7,52 & 14,71 & 12,72 & 6,63 & 10,26 \\
Chefe de família (\%) & 74,14 & 26,05 & 56,20 & 60,95 & 34,87 & 50,44 \\
Brancos (\%) & 42,33 & 44,71 & 43,22 & 37,91 & 42,87 & 39,92 \\
Não Brancos (\%) & 57,66 & 55,28 & 56,77 & 62,09 & 57,13 & 60,08 \\
\hline Fonte: Elaborada pelos
\end{tabular}

Fonte: Elaborada pelos autores, com base nos dados do IBGE/PNAD 2003-2013.

Notas: Trabalhadores ocupados a partir de 14 anos de idade. Os salários de 2003 foram reajustados para preços constantes de 2013 com base no IPCA acumulado

$\beta_{M k m i}^{*}=\left(\beta_{M_{K m i}}-\bar{\beta}_{m i}\right) ;$ sendo $i=A, B$

$L=$ variáveis continuas $(X)$

$M=$ quantidade de grupos de Dummies (ex. ocupação; setores e regiões)

$\mathrm{Km}=$ Categorias de cada grupo das dummies ( $\mathrm{K}-1$ ) (uma omitida)

$Y_{i}=\ln W$ (Logaritmo natural do salario hora);

$i=\mathrm{A}$ ou $\mathrm{B}$ (homem ou mulher)

$D_{k m i}=$ Dummy; $k=1,2,3 . . K m$ (dummies do modelo)

Obs. Inicia-se no $2(\mathrm{k}=2)$ porque a 1 foi omitida para evitar multicolinearidade perfeita.

$e_{i}=$ erro (aleatorio) 
p. 21 - Discriminação salarial de gênero no Centro-Oeste brasileiro: O preço do trabalho da mulher

Quanto aos aspectos referentes ao mercado de trabalho, os homens trabalhavam em média 47,8 horas por semana; tinham em média 24,5 anos de experiência, e 6,23 anos de estudos que Ihes rendiam um salário mensal médio de $\mathrm{R} \$$ 1.176,42. As mulheres, por sua vez, trabalhavam menos horas semanais, e apresentavam menor tempo de experiência no mercado de trabalho; os salários mensais femininos foram menores que os masculinos: sendo a média feminina de $R \$$ 800,46 por mês, em contraposição com a masculina de $\mathrm{R} \$ 1.176,42$.

Contudo, o aspecto educacional feminino revela que as mulheres apresentavam um período maior de estudo em relação aos homens. Assim, se experiência no trabalho, horas trabalhadas e educação influenciam os salários, muito embora o hiato entre gêneros possa ser explicado pelos dois primeiros fatores, o mesmo não é válido em relação à educação. Isto é percebido na análise dos salários horas: mesmo com níveis educacionais superiores aos de homens, a hora trabalhada feminina é menos valorada que a masculina, sendo de $R \$ 5,91$ para mulheres em relação a $R \$ 6,86$ para homens.

Diferentemente do que Araújo e Ribeiro (2002) constataram para meados da década de 1990, onde as médias de salários femininos e masculinos do Centro-Oeste eram superiores às nacionais, na década seguinte, em 2003, estas se revelaram inferiores às do Brasil: a média nacional para mulheres foi de $\mathrm{R} \$ 6,36$ a hora trabalhada, e de $\mathrm{R} \$ 7,45$ para os homens.

Quanto à divisão racial dos trabalhadores, as populações não brancas (tanto masculina como feminina) apresentaram um aumento da participação na força de trabalho da região em contraposição a um decréscimo da participação de trabalhadores brancos. O percentual de homens considerados chefes de família reduziu-se a 60,95\%, ao passo que para as mulheres esta média elevou-se para 34,87\%; a média de filhos reduziu-se no período.

Em relação às variáveis que designam as características produtivas, a experiência masculina manteve-se praticamente constante de um ano para o outro, enquanto que a feminina elevou-se. O nível de escolaridade dessa população revelou um aumento tanto para homens quanto para mulheres, e os salários mensais e salários horas entre os dois gêneros, apesar de mais elevados, ainda apresentaram divergências favoráveis aos homens.

\subsection{Análise das equações de determinação dos salários na região Centro-Oeste}

$\mathrm{Na}$ Tabela 2 são estimadas as equações salariais para homens e mulheres da região Centro-Oeste. Em 2003, as características produtivas acarretaram retornos positivos tanto para os homens quanto para as mulheres da região, assim como sugerem os pressupostos da teoria do capital humano.

No caso feminino, um ano a mais de educação e experiência rendiam às trabalhadoras um acréscimo de 7,05\% e 2,8\% em seus salários, respectivamente. Já a população de homens apresentou um nível maior de retornos salariais referentes a estas mesmas variáveis, sendo o retorno da educação masculina de 7,67\%, e o da 
experiência de 3,8\%. Em 2013, no geral, houve uma redução dos retornos desses fatores para os dois grupos, com destaque apenas para o retorno da educação feminina que no segundo período superou o da masculina.

Tabela 2 - Equações de salários horas para mulheres e homens do Centro-Oeste, 2003 e 2013

\begin{tabular}{l|cccccc}
\hline \multicolumn{1}{c|}{ Variáveis } & \multicolumn{5}{c}{2003} \\
\hline & Mulheres & Homens & Total & Mulheres & Homens & Total \\
\hline Anos de Estudos & $0,0704^{*}$ & $0,0767^{*}$ & $0,0744^{*}$ & $0,0555^{*}$ & $0,0477^{*}$ & $0,0504^{*}$ \\
Experiência & $0,0284^{*}$ & $0,0385^{*}$ & $0,0340^{*}$ & $0,0224^{*}$ & $0,0302^{*}$ & $0,0260^{*}$ \\
Experiência ${ }^{2}$ & $-0,0003^{*}$ & $-0,0004^{*}$ & $-0,0004^{*}$ & $-0,0003^{*}$ & $-0,0003^{*}$ & $-0,0003^{*}$ \\
Branco & $0,1197^{*}$ & $0,1526^{*}$ & $0,1403^{*}$ & $0,1740^{*}$ & $0,1367^{*}$ & $0,1511^{*}$ \\
Homem & - & - & $0,3137^{*}$ & - & - & $0,3934^{*}$ \\
Formal & $0,1570^{*}$ & $0,2205^{*}$ & $0,1928^{*}$ & $0,1127^{*}$ & $0,1133^{*}$ & $0,1129^{*}$ \\
Indústria Total & $-0,3366^{*}$ & $-0,0091$ & $-0,0375$ & $-0,1462^{*}$ & $-0,0152$ & $-0,0377$ \\
Comércio & $-0,2043^{*}$ & $-0,0248$ & $-0,0013$ & $-0,0829$ & $-0,0905^{*}$ & $-0,0761^{*}$ \\
Serviços & $-0,2461^{*}$ & $-0,0119$ & $-0,0059$ & $-0,0017$ & $-0,0213$ & 0,0082 \\
Dirigentes & $1,1280^{*}$ & $0,8927^{*}$ & $0,9706^{*}$ & $0,9353^{*}$ & $0,7788^{*}$ & $0,8310^{*}$ \\
PCAs & $1,1015^{*}$ & $1,0380^{*}$ & $1,0275^{*}$ & $0,7064^{*}$ & $0,9560^{*}$ & $0,8007^{*}$ \\
Técnicos & $0,4212^{*}$ & $0,4033^{*}$ & $0,3994^{*}$ & $0,2635^{*}$ & $0,2532^{*}$ & $0,2598^{*}$ \\
Urbano & $0,1116^{*}$ & $0,2171^{*}$ & $0,1838^{*}$ & 0,0395 & $0,2407^{*}$ & $0,1699^{*}$ \\
\hline Constante & $0,3966^{*}$ & 0,0410 & $-0,1127^{*}$ & $1,3046^{*}$ & $1,4894^{*}$ & $0,9676^{*}$ \\
\hline Fonte: Elaboradap
\end{tabular}

Fonte: Elaborada pelos autores com base nos dados da PNAD 2003 e 2013.

Nota: $\left({ }^{*}\right)$ significância a $5 \% ;\left({ }^{*}\right)$ significância a $10 \%$; sem asterisco, não significante.

Quanto à ocupação, em 2003, para os dois gêneros, os cargos de dirigentes e profissionais das ciências e das artes apresentaram os maiores retornos positivos comparativamente aos demais cargos, quando comparados ao cargo de trabalhadores operacionais. No entanto, diferentemente do ocorrido com as características produtivas, nas ocupações o retorno salarial feminino foi superior ao masculino para todos os postos de trabalho: em 2003 as mulheres dirigentes e as PCAs auferiram retornos de $113 \%$ e $110 \%$ sobre seus salários horas, respectivamente, enquanto que para os homens estes percentuais foram de $89,2 \%$ e de $103 \%$. Todavia, em 2013, novamente verifica-se uma diminuição destes retornos para os dois gêneros, revelando ainda que o retorno de homens PCA's superou o de mulheres neste mesmo posto.

Nos setores econômicos, para os dois grupos, os retornos salariais foram negativos em 2003, em relação ao setor agrícola, o qual por se tratar da região CentroOeste apresenta grande influência sobre o crescimento e desenvolvimento econômico da região. Em 2013, o retorno do setor industrial ${ }^{5}$ para mulheres elevou-se (apesar de manter-se negativo). As mulheres deste setor ganhavam $14,6 \%$ a menos que aquelas empregadas no setor agrícola.

A formalidade do mercado de trabalho também esteve atrelada a retornos positivos em relação à informalidade: no primeiro ano, ter carteira de trabalho assinada rendia um retorno de 15,7\% para as mulheres, e 22\% para os homens; em 2013, este retorno se equiparou para ambos os grupos (aproximadamente 11\%).

\footnotetext{
${ }^{5}$ Para os demais setores os resultados não foram significativos em 2013.
} 
p. 23 - Discriminação salarial de gênero no Centro-Oeste brasileiro: O preço do trabalho da mulher

Na característica não produtiva cor de pele, a pele branca garantia um retorno superior em relação à pele não branca, tanto feminina quanto masculina. Em 2003, o retorno para as mulheres brancas foi de $11,9 \%$ a mais em relação às não brancas; entre a população masculina o impacto foi de 15,2\%. Em 2013, houve um aumento do retorno atribuído a esta característica para as mulheres $(17,4 \%)$, enquanto que o retorno de homens brancos em relação a não brancos reduziu-se a 13,7\% sobre seus salários horas.

Por fim, no impacto referente à região em que estas populações ocupadas residiam, para ambos os gêneros estar situado em regiões urbanas acarretava retornos positivos sobre os salários em relação à região rural. Em 2003, este retorno salarial masculino foi superior ao feminino (sendo de $21,7 \%$ e 11,2\%, respectivamente); já em 2013, o impacto desta variável aumentou.

\subsection{Decomposições salariais de Oaxaca-Blinder para a região Centro-Oeste do Brasil: a discriminação de gênero}

Nesta seção são apresentadas as diferenças salariais entre gêneros da região Centro-Oeste, e a decomposição destes hiatos em parcelas explicadas e não explicadas (proxy da discriminação). Para efeitos de contextualização, Tabela 3 apresenta os dados da decomposição salarial para o Brasil, nos respectivos anos de 2003 e 2013.

De acordo com os dados, em 2003 os trabalhadores brasileiros ganhavam 8,41\% a mais que as trabalhadoras, e este diferencial entre os anos elevou-se para $9,11 \%$. 0 total desta diferença explicado pela série de variáveis consideradas indicou que no primeiro ano, caso os fatores femininos fossem equiparados aos masculinos, os salários das mulheres sofreriam uma redução de 18,79\%. Todavia, este impacto negativo reduziu-se para 17,6\% nos salários femininos em 2013, o que sugere uma possível melhora nas variáveis masculinas.

As variáveis explicadas que mais contribuíram para este montante em ambos os períodos foram os aspectos produtivos, a ocupação e o setor. Em 2003, se os aspectos produtivos (como educação e experiência) de homens e mulheres fossem igualados no país, os salários femininos teriam uma redução de 8,05\%; em 2013, este impacto diminuiu para $-6,68 \%$.

Os dados para as diferenças não explicadas (ou discriminação de gênero) apontam o impacto no salário feminino dado somente pelo fator discriminante do mercado de trabalho. No caso brasileiro em 2003, na ausência deste fator, as remunerações femininas se elevariam em 33,5\%; ao longo dos dois anos houve uma redução deste impacto: o aumento no salário feminino seria de $32,42 \%$ sem a presença de discriminação.

Para a análise das diferenças e da discriminação salarial no Centro-Oeste brasileiro segue a decomposição salarial entre as remunerações de homens e mulheres ocupados da região em 2003 e 2013 (Tabela 4). Em 2003, a população masculina ganhava em média $12,16 \%$ a mais que a população feminina, havendo ainda uma elevação deste hiato entre os períodos, chegando esta diferença a 19,8\% em 2013. 
Comparativamente ao nível nacional, nota-se que o hiato salarial na região não esteve somente acima da média do país, como também cresceu mais rapidamente entre os anos, chegando a superar o nacional em $10 \mathrm{pp}$.

Tabela 3 - Decomposição de Oaxaca-Blinder para diferença de rendimentos salariais de homens e mulheres no Brasil para 2003 e 2013

\begin{tabular}{|c|c|c|c|c|c|c|}
\hline \multirow[t]{2}{*}{ Grupos } & \multicolumn{4}{|c|}{ Coeficientes do salário } & \multicolumn{2}{|c|}{$\begin{array}{c}\text { Coeficientes na } \\
\text { forma exponencial }\end{array}$} \\
\hline & \multicolumn{2}{|c|}{2003} & \multicolumn{2}{|c|}{2013} & 2003 & 2013 \\
\hline Homens & \multicolumn{2}{|c|}{1,4154} & \multicolumn{2}{|c|}{1,9324} & $4,11^{*}$ & $6,9^{*}$ \\
\hline Mulheres & \multicolumn{2}{|c|}{1,3346} & \multicolumn{2}{|c|}{1,8457} & $3,8^{*}$ & $6,33^{*}$ \\
\hline Diferenças & Coeficientes & $\begin{array}{l}\text { Participação } \\
\text { relativa (\%) }\end{array}$ & Coeficientes & $\begin{array}{c}\text { Participação } \\
\text { relativa (\%) }\end{array}$ & $\begin{array}{r}\text { Imp } \\
\text { percen } \\
\text { sal }\end{array}$ & $\begin{array}{l}\text { cto } \\
\text { ual no } \\
\text { io }\end{array}$ \\
\hline Explicada Total & $-0,2081$ & $-257,67$ & $-0,1936$ & $-222,11$ & $-18,79 *$ & $-17,6^{*}$ \\
\hline Cor de pele & $-0,0056$ & $-7,03$ & $-0,0054$ & $-6,26$ & $-0,57^{*}$ & $-0,54 *$ \\
\hline Aspectos produtivos & $-0,0839$ & $-103,88$ & $-0,0691$ & $-79,3$ & $-8,05^{*}$ & $-6,68 *$ \\
\hline Ocupação & $-0,0489$ & $-60,6$ & $-0,0653$ & $-74,91$ & $-4,78^{*}$ & $-6,32 *$ \\
\hline Setor & $-0,043$ & $-53,27$ & $-0,0306$ & $-35,17$ & $-4,21^{*}$ & $-3,02 *$ \\
\hline Mercado Formal & $-0,0069$ & $-8,58$ & $-0,0028$ & $-3,23$ & $-0,69 *$ & $-0,28 *$ \\
\hline Região Urbana & $-0,009$ & $-11,14$ & $-0,0125$ & $-14,38$ & $-0,9 *$ & $-1,25^{*}$ \\
\hline Região & $-0,0106$ & $-13,14$ & $-0,0077$ & $-8,84$ & $-1,06^{*}$ & $-0,77^{*}$ \\
\hline $\begin{array}{l}\text { Discriminação de } \\
\text { gênero }\end{array}$ & 0,2888 & 357,67 & 0,2808 & 322,11 & $33,5^{*}$ & $32,42^{*}$ \\
\hline Diferença total & 0,0807 & 100 & 0,0871 & 100,00 & $8,41^{*}$ & $9,11^{*}$ \\
\hline
\end{tabular}

Tabela 4 - Decomposição de Oaxaca-Blinder para diferença de rendimentos salariais de homens e mulheres no Centro-Oeste, para 2003 e 2013

\begin{tabular}{|c|c|c|c|c|c|c|}
\hline \multirow[t]{2}{*}{ Grupos } & \multicolumn{4}{|c|}{ Coeficientes do salário } & \multicolumn{2}{|c|}{$\begin{array}{c}\text { Coeficientes na forma } \\
\text { exponencial }\end{array}$} \\
\hline & \multicolumn{2}{|c|}{2003} & \multicolumn{2}{|c|}{2013} & 2003 & 2013 \\
\hline Homens & \multicolumn{2}{|c|}{1,452} & \multicolumn{2}{|c|}{2,064} & $4,27^{*}$ & $7,87^{*}$ \\
\hline Mulheres & \multicolumn{2}{|c|}{1,3372} & \multicolumn{2}{|c|}{1,8833} & $3,8^{*}$ & $6,57 *$ \\
\hline Diferenças & Coeficientes & $\begin{array}{c}\text { Participação } \\
\text { relativa (\%) }\end{array}$ & Coeficientes & $\begin{array}{c}\text { Participação } \\
\text { relativa (\%) }\end{array}$ & $\begin{array}{r}\text { Impacto } \\
\mathrm{S}\end{array}$ & $\begin{array}{l}\text { centual no } \\
\text { rio }\end{array}$ \\
\hline Explicada Total & $-0,1565$ & $-136,34$ & $-0,1357$ & $-75,11$ & $-14,49 *$ & $-12,69 *$ \\
\hline Cor de pele & $-0,0035$ & $-3,05$ & $-0,0065$ & $-3,6$ & $-0,35^{*}$ & $-0,65^{*}$ \\
\hline $\begin{array}{l}\text { Aspectos } \\
\text { produtivos }\end{array}$ & $-0,0897$ & $-78,17$ & $-0,0613$ & $-33,94$ & $-8,58^{*}$ & $-5,95^{*}$ \\
\hline Ocupação & $-0,0352$ & $-30,69$ & $-0,0576$ & $-31,89$ & $-3,46^{*}$ & $-5,6^{*}$ \\
\hline Setor & 0,0027 & 2,41 & 0,0039 & 2,21 & 0,28 & 0,4 \\
\hline Mercado Formal & $-0,0084$ & $-7,33$ & 0,0001 & 0,07 & $-0,84^{*}$ & 0,01 \\
\hline Região Urbana & $-0,0223$ & $-19,49$ & $-0,0143$ & $-7,96$ & $-2,21^{*}$ & $-1,43^{*}$ \\
\hline $\begin{array}{l}\text { Discriminação de } \\
\text { gênero }\end{array}$ & 0,2712 & 236,34 & 0,3164 & 175,11 & $31,17^{*}$ & $37,22 *$ \\
\hline Diferença total & 0,1147 & 100 & 0,1806 & 100 & $12,16^{*}$ & $19,8^{*}$ \\
\hline
\end{tabular}

Fonte: Elaborada pelos autores com base nos dados da PNAD 2003 e 2013.

Nota: $\left({ }^{*}\right)$ significância a 5\%; $(* *)$ significância a $10 \%$. 
p. 25 - Discriminação salarial de gênero no Centro-Oeste brasileiro: O preço do trabalho da mulher

Decompondo estas diferenças em parcelas explicadas e não explicadas (ou discriminação salarial), no primeiro ano o impacto total das diferenças explicadas refletiria uma redução de aproximadamente $14,5 \%$ nos salários femininos, caso as características das mulheres fossem equiparadas às dos homens. Já em 2013, houve a redução deste percentual $(-12,7 \%)$, o que indica que a "perda" salarial feminina seria menor, sugerindo assim uma melhora nos fatores masculinos; em relação ao país, o impacto das diferenças explicadas na região foi consideravelmente menor. Ademais, nos dois períodos, os aspectos produtivos, a ocupação e a área censitária foram características importantes na composição da parcela explicada.

No que se refere à discriminação salarial, os dados apontam que na ausência deste fenômeno os salários femininos da região se elevariam em 31,17\% em 2003, impacto menor do que o ocorrido no país no mesmo ano (33,5\%). Todavia, em 2013, a elevação salarial para as mulheres passaria a ser de $37,22 \%$, fato que constata o aumento da discriminação salarial entre gêneros na região, em contrapartida com a diminuição deste fenômeno no país neste segundo período (32,42\%).

Tabela 5 - Decomposição de Oaxaca-Blinder para diferença de rendimentos salariais de homens e mulheres brancos no Centro-Oeste, para 2003 e 2013

\begin{tabular}{|c|c|c|c|c|c|c|}
\hline \multirow[t]{2}{*}{ Grupos } & \multicolumn{4}{|c|}{ Coeficientes do salário } & \multicolumn{2}{|c|}{$\begin{array}{c}\text { Coeficientes na } \\
\text { forma exponencial }\end{array}$} \\
\hline & \multicolumn{2}{|c|}{2003} & \multicolumn{2}{|c|}{2013} & 2003 & 2013 \\
\hline Homens brancos & \multicolumn{2}{|c|}{1,6574} & \multicolumn{2}{|c|}{2,2193} & $5,24 *$ & $9,2^{*}$ \\
\hline Mulheres brancas & \multicolumn{2}{|c|}{1,5167} & \multicolumn{2}{|c|}{2,0514} & $4,55^{*}$ & $7,77^{*}$ \\
\hline Diferenças & Coeficientes & $\begin{array}{c}\text { Participação } \\
\text { relativa (\%) }\end{array}$ & Coeficientes & $\begin{array}{c}\text { Participação } \\
\text { relativa (\%) }\end{array}$ & \multicolumn{2}{|c|}{$\begin{array}{c}\text { Impacto percentual } \\
\text { no salário }\end{array}$} \\
\hline Explicada Total & $-0,1584$ & $-112,64$ & $-0,1475$ & $-87,92$ & $-14,65^{*}$ & $-13,72^{*}$ \\
\hline $\begin{array}{l}\text { Aspectos } \\
\text { produtivos }\end{array}$ & $-0,0936$ & $-66,57$ & $-0,0638$ & $-38,06$ & $-8,94^{*}$ & $-6,19 *$ \\
\hline Ocupação & $-0,0532$ & $-37,87$ & $-0,0783$ & $-46,64$ & $-5,19 *$ & $-7,53^{*}$ \\
\hline Setor & 0,0205 & 14,61 & 0,0101 & 6,07 & 2,08 & 1,02 \\
\hline Mercado Formal & $-0,0099$ & $-7,04$ & 0,0001 & 0,1 & $-0,99 *$ & 0,02 \\
\hline Região Urbana & $-0,0221$ & $-15,77$ & $-0,0157$ & $-9,39$ & $-2,19 *$ & $-1,56^{*}$ \\
\hline $\begin{array}{l}\text { Discriminação de } \\
\text { gênero }\end{array}$ & 0,2991 & 212,64 & 0,3154 & 187,92 & $34,86^{*}$ & $37,09 *$ \\
\hline Diferença total & 0,1406 & 100 & 0,1678 & 100,00 & $15,1^{*}$ & $18,28^{*}$ \\
\hline
\end{tabular}

Para um maior detalhamento em relação à cor da pele, a Tabela 5 expõe a decomposição entre salários masculinos e femininos para a população branca da região Centro-Oeste nos anos de 2003 e 2013. Em 2003, os salários de homens brancos da região foi 15,1\% maior que os salários de mulheres brancas; em 2013 a diferença salarial entre estes dois grupos elevou-se para 18,28\%.

Quanto às diferenças explicadas totais, no primeiro ano os salários femininos teriam que se reduzir em $14,65 \%$, caso as características das mulheres brancas fossem equiparadas às dos homens brancos. Em 2013, o impacto total foi de $-13,72 \%$ nos salários femininos, o que comparativamente a 2003, revela que as "perdas" femininas 
se tornaram menos acentuadas entre a população branca. Entre as variáveis mais influentes destacam-se novamente os aspectos produtivos, a ocupação, e a região em que habita. Assim, se em 2003 a capacitação profissional feminina fosse igualada à masculina, os salários das mulheres reduziriam 8,94\%. Em 2013, o sinal negativo dos impactos percentuais indicou redução destes salários de 6,19\% quanto aos aspectos produtivos.

Em relação à discriminação salarial, na ausência do fenômeno em 2003 os salários de mulheres brancas da região aumentariam em 34,86\%. No segundo ano o montante da parcela não explicada elevou-se para 37,1\%, o que indicou aumento da discriminação na região. Como visto, durante a década de 1990, Bohnenberger (2005) constatou que houve reduções na discriminação salarial entre gêneros no Centro-Oeste brasileiro, todavia, afirmava que esta diminuição foi a mais inexpressiva em relação às demais macrorregiões, tanto para brancas quanto não brancas.

Esta pesquisa, então, avançou no estudo da decomposição das diferenças salariais entre homens e mulheres não brancos do Centro-Oeste, e o comparativo entre os anos estudados são expostos na Tabela 6. Em 2003 os salários dos homens não brancos eram 11,6\% maiores que os salários de mulheres não brancas. Em 2013, ocorreu uma elevação significativa deste hiato salarial, o qual chegou a alcançar $23,5 \%$.

Tabela 6 - Decomposição de Oaxaca-Blinder para diferença de rendimentos salariais de homens e mulheres não brancos no Centro-Oeste, para 2003 e 2013

\begin{tabular}{|c|c|c|c|c|c|c|}
\hline \multirow[t]{2}{*}{ Grupos } & \multicolumn{4}{|c|}{ Coeficientes do salário } & \multicolumn{2}{|c|}{$\begin{array}{c}\text { Coeficientes na } \\
\text { forma } \\
\text { exponencial }\end{array}$} \\
\hline & \multicolumn{2}{|c|}{2003} & \multicolumn{2}{|c|}{2013} & 2003 & 2013 \\
\hline Homens não brancos & \multicolumn{2}{|c|}{1,3013} & \multicolumn{2}{|c|}{1,9736} & $3,67^{*}$ & $7,19 *$ \\
\hline Mulheres não brancas & \multicolumn{2}{|c|}{1,1916} & \multicolumn{2}{|c|}{1,7622} & $3,29 *$ & $5,82 *$ \\
\hline Diferenças & Coeficientes & $\begin{array}{c}\text { Participação } \\
\text { relativa (\%) }\end{array}$ & Coeficientes & $\begin{array}{c}\text { Participação } \\
\text { relativa (\%) }\end{array}$ & $\begin{array}{r}\operatorname{Imp} \\
\text { percen } \\
\text { salc }\end{array}$ & $\begin{array}{l}\text { cto } \\
\text { ual no } \\
\text { io }\end{array}$ \\
\hline Explicada & $-0,1383$ & $-126,1$ & $-0,1033$ & $-48,9$ & $-12,92^{*}$ & $-9,82 *$ \\
\hline Aspectos produtivos & $-0,0774$ & $-70,57$ & $-0,0533$ & $-25,21$ & $-7,45^{*}$ & $-5,19 *$ \\
\hline Ocupação & $-0,0195$ & $-17,81$ & $-0,037$ & $-17,5$ & $-1,94^{*}$ & $-3,63 *$ \\
\hline Setor & $-0,0136$ & $-12,43$ & $-0,0006$ & $-0,29$ & $-1,36$ & $-0,06$ \\
\hline Mercado Formal & $-0,006$ & $-5,44$ & 0,0004 & 0,2 & $-0,60 *$ & 0,04 \\
\hline Região Urbana & $-0,0217$ & $-19,83$ & $-0,0128$ & $-6,08$ & $-2,15^{*}$ & $-1,28 *$ \\
\hline $\begin{array}{l}\text { Discriminação de } \\
\text { gênero }\end{array}$ & 0,248 & 226,1 & 0,3147 & 148,9 & $28,16^{*}$ & $37^{*}$ \\
\hline Diferença total & 0,1097 & 100 & 0,2114 & 100,00 & $11,60 *$ & $23,54^{*}$ \\
\hline
\end{tabular}

Fonte: Elaborada pelos autores com base nos dados da PNAD 2003 e 2013.

Nota: $(*)$ significância a $5 \% ;(* *)$ significância a $10 \%$.

Analisando o montante das diferenças explicadas no primeiro ano, ao igualar as características dos trabalhadores não brancos, as mulheres desta população teriam uma redução 12,92\% em seus salários; tal fato indica que as trabalhadoras negras do Centro-Oeste (bem como as brancas) não obtêm seus salários valorados da mesma maneira que os trabalhadores homens da região. No segundo período, dadas às 
p. 27 - Discriminação salarial de gênero no Centro-Oeste brasileiro: O preço do trabalho da mulher

mesmas circunstâncias, os salários das mulheres não brancas sofreriam uma redução de 9,82\%; este impacto em 2003 foi mais acentuado que em 2013.

Quanto às variáveis componentes da parcela explicada, destaca-se a influência das características produtivas, as quais, quando igualadas entre os gêneros, acarretariam uma redução de 7,45\% no salário feminino em 2003, que posteriormente passou a ser de 5,19\% em 2013. No que tange a discriminação salarial, em 2003 as mulheres não brancas teriam os salários elevados em $28,16 \%$ caso não houvesse a ocorrência do fenômeno; em 2013, houve um aumento significativo deste impacto: $37 \%$. Isto indica que a parcela da disparidade salarial entre os gêneros dada somente pelo fato de ser mulher elevou-se consideravelmente em $37 \%$ entre os trabalhadores não brancos, população predominante na região

Tabela 7 - Síntese da Decomposição de Oaxaca-Blinder por gênero no Centro-Oeste, para 2003 e 2013

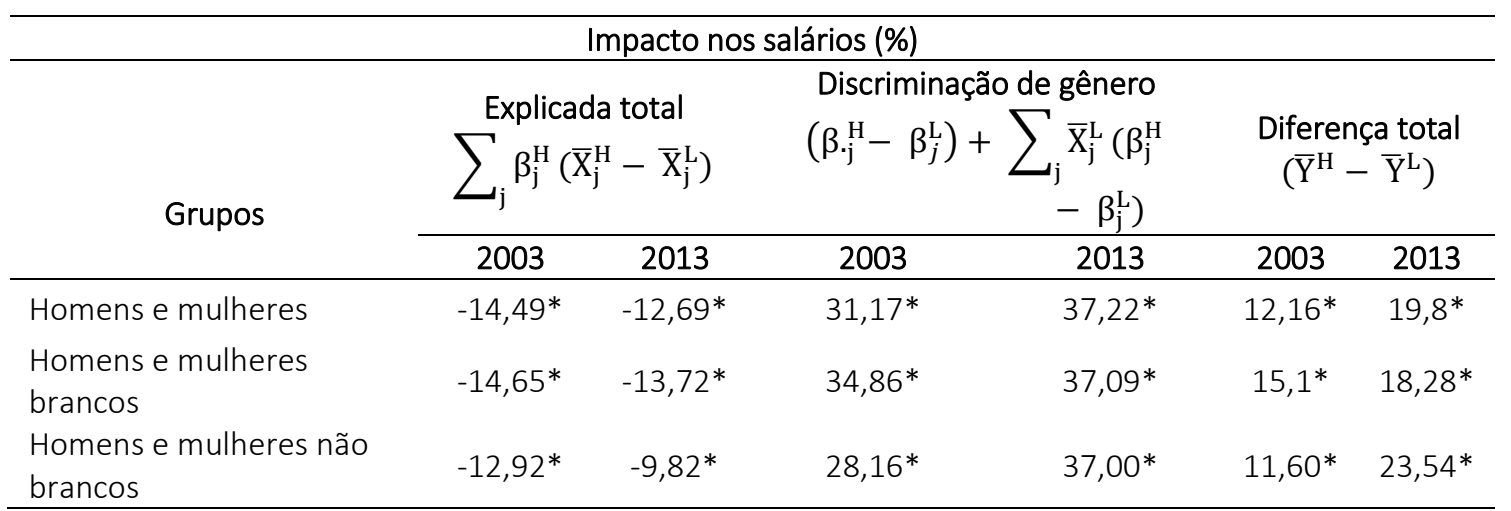

Fonte: Elaborada pelos autores com base nos dados da PNAD 2003 e 2013.

Nota 1: Para minimizar o problema de heterocedasticidade, comum em modelos de determinação de salários, utilizou-se o procedimento de erros robusto de White (1980). Nota 2: $\left({ }^{*}\right)$ significância a 5\%; $\left({ }^{* *}\right)$ significância a 10\%; sem asterisco, não significante.

As fontes da diferenciação salarial para o Centro-Oeste brasileiro estão sintetizadas na Tabela 7. Ficam evidentes: i) o aumento dos diferenciais salariais na região, na contramão das constatações para o país reveladas pela literatura, como em Leme e Wajnman (2000) e Bohnenberger (2005); ii) a discriminação sexual como a principal causa do hiato salarial e seu incremento nos anos analisados; e iii) a redução da contribuição das fontes derivadas dos atributos produtivos e dos postos de trabalho para a melhoria desse descompasso de salários.

\section{CONCLUSÃO}

O principal objetivo deste trabalho foi mensurar e analisar a discriminação salarial por gênero na região Centro-Oeste do Brasil nos anos de 2003 e 2013. Em relação ao perfil da população ocupada na região, verificou-se que os homens possuem maior tempo de experiência no trabalho em relação às mulheres, e apesar da evolução positiva nos anos em análise o nível educacional feminino da região foi superior ao masculino nos dois períodos; todavia, a hora trabalhada masculina foi mais valorada 
que a feminina.

Confirmou-se a presença de discriminação salarial de gênero no Centro-Oeste brasileiro, sendo este impacto em 2003, inferior ao do Brasil. No entanto, enquanto a discriminação em nível nacional reduziu-se ao longo do período, a em nível regional elevou-se no segundo ano (2013), superando a do país.

A maior parcela da população ocupada do Centro-Oeste era composta por indivíduos não brancos, e em 2003, a discriminação salarial entre os brancos era mais acentuada que entre os não brancos; o mesmo é percebido em relação às diferenças salariais entre homens e mulheres dos dois grupos de cor de pele. Em 2013, ambas as discriminações de gênero entre brancos e não brancos se elevaram. O mesmo movimento também pôde ser percebido no comportamento das diferenças salariais entre homens e mulheres de ambos os grupos.

Além disso, se equiparados fatores como atributos produtivos e postos de trabalho entre homens e mulheres, isto refletiu na diminuição dos salários femininos em ambos os anos. Todavia, os impactos destas variáveis diminuíram no período, o que significa uma melhora do hiato salarial.

Considerando-se que a literatura acerca de diferenças salariais na região ainda seja bastante incipiente, os resultados expostos nesta pesquisa, além de contribuírem para uma melhor visão das disparidades salariais do Centro-Oeste no que tange ao gênero, também podem servir como instrumento para a elaboração de políticas públicas para a região que visem à minimização do problema de discriminação salarial contra as mulheres, principalmente por conta da evolução desfavorável deste fenômeno na região.

\section{REFERÊNCIAS}

ARAÚJO, V. F.; RIBEIRO, E. P. Diferencias de salários por gênero no Brasil: Uma análise regional. Revista Econômica do Nordeste, Fortaleza, v.33, abr/jun. 2002.

BARROS, R. P.; MENDONÇA, R. S. P. Diferenças entre discriminação racial e por gênero e o desenho de políticas anti-discriminatórias. Estudos Feministas, v. 183, n. 1, 1996.

BARROS, R. P.; MENDONÇA, R. S. P. Os determinantes da desigualdade no Brasil. Rio de Janeiro: Instituto de Pesquisa Econômica Aplicada, 1995. (Texto para Discussão, n. 377).

BECKER, G. S. Investment in Human Capital: A Theoretical Analysis. Journal of Political Economy, v. 70, n. 5, Part 2: Investment in Human Beings, p.9-4, out. 1962.

BOHNENBERGER, R. Uma análise regional da discriminação de gênero e raça no mercado de trabalho brasileiro - 1992 a 2001. 2005. 174 f. Dissertação (Mestrado em Economia de Empresas) - Instituto de Economia, Universidade Católica de Brasília, Brasília, 2005. 
p. 29 - Discriminação salarial de gênero no Centro-Oeste brasileiro: O preço do trabalho da mulher

BONELLI, R.; RAMOS, L. Distribuição de renda no Brasil: avalição das tendências de longo prazo e mudanças na desigualdade desde de meados dos anos 70 . Revista de Economia Política, v. 13, n. 2, abr/jun. 1993.

BORJAS, G. J. Economia do Trabalho. Porto Alegre: AMGH, 2012.

CAMBOTA, J. N.; PONTES, P. A. Desigualdade de rendimentos por gênero intraocupações no Brasil, em 2004. Revista de Economia Contemporânea, Rio de Janeiro, v.11, n.2, p.331-350, maio/ago. 2007.

CARVALHO, A. P.; NÉRI, M. C.; SILVA, D. B. N. Diferenciais de salários por raça e gênero no Brasil: aplicação dos procedimentos de Oaxaca e Heckman em pesquisas amostrais complexas. In: ENCONTRO NACIONAL DE ESTUDOS POPULACIONAIS, 15., 2006, Caxambu. Anais... Caxambu: ABEP, 2006.

EHRENBERG, R. G.; SMITH, R. S. A Moderna Economia do Trabalho. São Paulo, Makron Books, 2000.

FIUZA-MOURA, F. K. Diferenciais de salário na indústria brasileira por sexo, cor e intensidade tecnológica. 96 f. Dissertação (Mestrado em Economia Regional) Centro de Estudos Sociais Aplicados, Universidade Estadual de Londrina. Londrina, 2015.

GOMES, M. R. Discriminação salarial de gênero e alocação por setor econômico dos trabalhadores no Primeiro emprego, Reemprego e Remanescentes: regiões Sul e Nordeste do Brasil. 131 f. Dissertação (Mestrado em Economia Regional) Centro de Estudos Sociais Aplicados, Universidade Estadual de Londrina, Londrina, 2016.

IPEA. Ipeadata: base de dados macroeconômicos e regionais, 2003 - 2013. Disponível em: < http://www.ipeadata.gov.br/> Acesso em: 21 jun. 2016.

LANGONI, C. G. Distribuição da renda e desenvolvimento econômico no Brasil: uma reafirmação. Ensaios Econômicos, Rio de Janeiro, n. 7, 1973.

LEME, M. C. S.; WAJNMAN, S. Tendências de coorte nos diferenciais de rendimentos por sexo. In: HENRIQUES, R. (Org.). Desigualdade e pobreza no Brasil. Rio de Janeiro: IPEA, 2000.

LIMA, R. Mercado de trabalho: o capital humano e a teoria da segmentação. Pesquisa de Planejamento Econômico. Rio de Janeiro, v. 10, p.217-272, abr. 1980.

LOVELL, P. A. Race, Gender, and Development in Brazil. Latin American Research, v.29, n.3, p. 7-35, 1994.

MANGANELLI, Anelise. Diferenciais de salários entre homens e mulheres no Brasil: 0 "Teto de Vidro". In: CONGRESSO LATINO-AMERICANO DE ESTUDOS DO TRABALHO. O TRABALHO NO SÉCULO XXI. MUDANÇAS, IMPACTOS E PERSPECTIVAS, 7., 2013, Porto Alegre. Anais... Porto Alegre: Pontifícia Universidade Católica do Rio Grande do Sul, 2013.

MINCER, J. Shcooling, experience and earnings. New York: NBER,1974. 
Priscila A. Hayashi; Solange de Cassia I. de Souza; Magno R. Gomes e Katy Maia - p.30

OAXACA, R. Male-female wage differentials in urban labor markets. International economic review, p. 693-709, 1973.

PNAD, Pesquisa Nacional por Amostras de Domicílios. Microdados reponderados da PNAD, 2001 - 2014. Disponível em: http://www.ibge.gov.br/home/estatistica/

populacao/trabalhoerendimento/pnad2014/microdados.shtm> Acesso em: 19/06/2016>.

SCHULTZ, T. W. Investment in Human Capital. The American Economic Review, v. 51, n. 1, mar. 1961, p.1-17.

SILVA, W. L. C.; YASUNAKA, L. Y.; MELO, M. F. S. Análise Socioeconômica e Produtiva da Região Centro-Oeste: Posicionamento Estratégico e Criação de Valor do Estado do Mato Grosso Do Sul. In: XV SIMPOI, 15., 2012, São Paulo. Anais... São Paulo: FGVSP, 2012.

YUN, M. A simple solution to the identification problem in detailed wage decompositions. New Orleans, Tulane University: 2003. (IZA Discussion Paper n.836).

YUN, M. A Simple Solution to the Identification Problem in Detailed Wage Decompositions. Economic Inquiry, v. 43, Issue 4, p. 766-772, 2005. 